\title{
Precision of farmer-based fertility ratings and soil organic carbon for crop production on a Ferralsol
}

\author{
P. Musinguzi ${ }^{1}$, P. Ebanyat ${ }^{1,2}$, J. S. Tenywa ${ }^{1}$, T. A. Basamba ${ }^{1}$, M. M. Tenywa ${ }^{1}$, and D. Mubiru ${ }^{3}$ \\ ${ }^{1}$ Department of Agricultural Production, Makerere University, P.O. Box 7062, Kampala, Uganda \\ ${ }^{2}$ International Institute of Tropical Agriculture (IITA), Plot 15, Naguru East Road, P.O. Box 7878, Kampala, Uganda \\ ${ }^{3}$ National Agricultural Research Laboratories, Kawanda, P.O. Box 7064 Kampala, Uganda \\ Correspondence to: P. Musinguzi (musipato@yahoo.com)
}

Received: 2 February 2015 - Published in Solid Earth Discuss.: 31 March 2015

Revised: 11 August 2015 - Accepted: 12 August 2015 - Published: 17 September 2015

\begin{abstract}
Simple and affordable soil fertility ratings are essential, particularly for the resource-constrained farmers in sub-Saharan Africa (SSA), in planning and implementing prudent interventions. A study was conducted on Ferralsols in Uganda to evaluate farmer-based soil fertility assessment techniques, hereafter referred to as farmers' field experiences (FFE), for ease of use and precision, against more formal scientific quantitative ratings using soil organic carbon (SQRSOC). A total of 30 fields were investigated and rated using both techniques, as low, medium and high in terms of soil fertility - with maize as the test crop. Both soil fertility rating techniques were fairly precise in delineating soil fertility classes, though the FFE was inefficient in distinguishing fields $>1.2 \%$ SOC with medium and high fertility. Soil organic carbon, silt and clay were exceptionally influential, accounting for the highest percentage in grain yield of $50 \%$ in the topsoil $(0-15 \mathrm{~cm})$ and $67 \%$ for the mean concentrations from 0 to 15 and 15 to $30 \mathrm{~cm}$. Each unit increase in SOC concentration resulted in 966 to $1223 \mathrm{~kg} \mathrm{ha}^{-1}$ yield gain. The FFE technique was effective in identifying lowfertility fields, and this was coherent with the fields categorized as low (SOC $<1.2 \%$ ). Beyond this level, its precision can be remarkably increased when supplemented with the SQR-SOC technique.
\end{abstract}

\section{Introduction}

Globally, land degradation has increased drastically, limiting crop productivity and income security. In response, several studies have been conducted with different scientific in- terventions to restore degraded land quality (Shazana et al., 2013; Novara et al., 2013; Tesfaye et al., 2014). However, some interventions have remained unfeasible and unaffordable for effective land quality restoration. In sub-Saharan Africa (SSA), limited knowledge on the state of soil fertility and the extent of depletion remains a major challenge to crop production (Bekunda et al., 2010). Knowledge on the interdisciplinary roles of soil in controlling geochemical and hydrological cycles to meet societal needs to be scaled out (Brevik et al., 2015; Keesstra et al., 2012). Soil fertility assessment is crucial for effective land resource management as well as ensuring sustainable agricultural productivity and environmental health (Andrews et al., 2004; IFDC, 2006). Most developed countries are privileged to possess comprehensive, sophisticated and easily accessible laboratory facilities for their farming communities. The reverse is true for the bulk of farming communities in SSA, where soil degradation has reached insurmountable levels (African Agriculture Status Report, 2013). Scientific approaches for soil fertility assessment are nearly inconceivable in the region owing to limited and costly laboratory services available. Consequently, efforts that would guide soil management in the region cannot be as progressive as would be expected amidst such economic distresses. This affects soil quality and increases vulnerability of farmers to hunger, food insecurity and poverty. Soil fertility in smallholder farming systems in SSA is characterized by heterogeneity, especially in continuously cultivated fields (Ebanyat, 2009; Tittonell et al., 2007). Availability of effective farmer-based soil fertility assessment techniques is imperative to achieve prompt, cost-effective and user-friendly tools culminating into high water and nutrient 


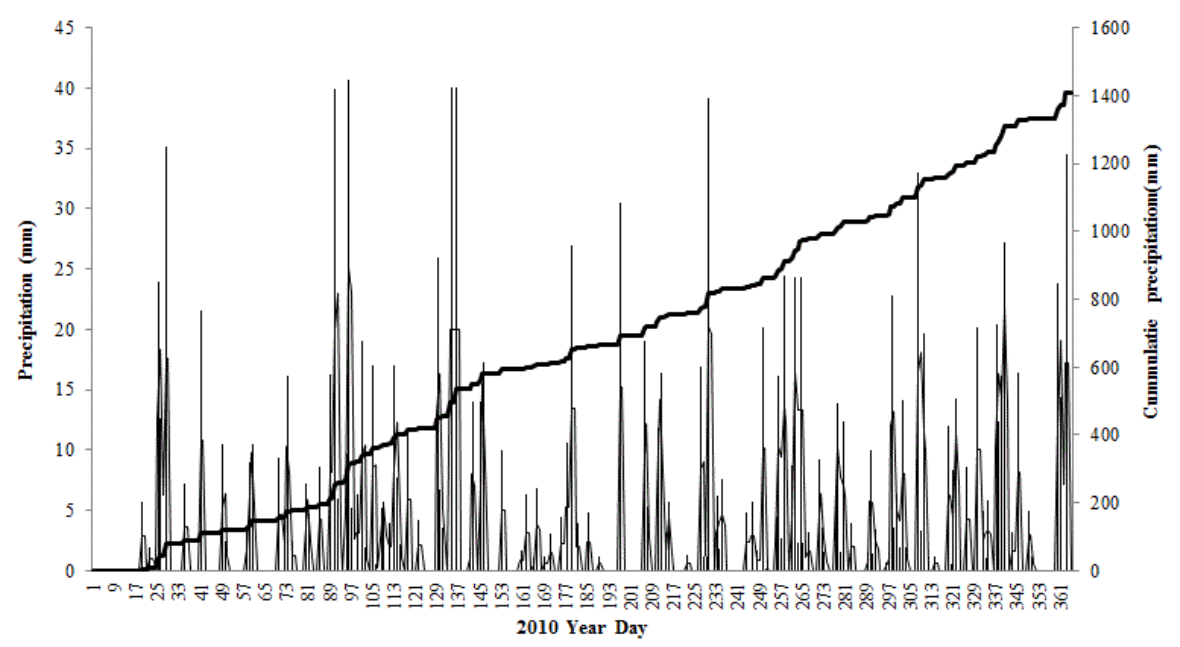

Figure 1. Daily and cumulative precipitation for 2010 in Kiboga district, Uganda.

efficiency, high crop yield gains and effective land-use planning (Araya et al., 2011).

Several farmer-based soil productivity assessment techniques have been documented in SSA. The main ones are (i) use of local farmers' field experiences, with or without the support of experienced neighbors or front-line workers (Payton et al., 2003; Tesfahunegn et al., 2011); (ii) use of GIS technology with infrared spectroscopy for rapid soil analysis (Shepherd et al., 2003); and (iii) use of soil test kits and visual plant deficiency symptoms for rapid fertility assessment (Sanginga and Woomer, 2009). However, simple soil fertility rating using the FFE approach is reportedly most promising in predicting soil productivity (Karltun et al., 2013; Talawar and Rhoades, 1998; Tesfahunegn et al., 2011). The technique is affordable, rapid and simple to use since it is based on community indigenous knowledge (Corbeels et al., 2000; Payton et al., 2003; Schoonmaker Freudenberger, 1994). However, this technique still requires refinement against the conventional scientific qualitative assessments so as to improve relevance and accuracy. Once proven, it will enable effective recommendations to guide soil fertility and judicious nutrient management for sustainable crop production.

Soil organic carbon (SOC) is a modern, fairly reliable and field-based soil quality indicator for assessing yield (Carter et al., 2003; Lal, 2006). It is a major player in climate change and nutrient cycling with significant amounts of terrestrial carbon stored in the soil (Lorenz and Lal, 2014; Kukal et al., 2014). However, SOC can be depleted easily through use of inappropriate management practices (Rinivasarao et al., 2014; Barua and Haque, 2013). Proper management of SOC is key for sustainable crop production since it can be used as a soil quality indicator for farmers. The application of SOC as a single indicator can save a farmer colossal sums of money compared to complete soil fertility assessment, which includes chemical ( $\mathrm{pH}, \mathrm{SOC}$, active organic matter, electri- cal conductivity, total nitrogen, phosphorus and potassium), physical (texture, bulk density, soil depth and water holding capacity) and biological (microbial biomass, mineralizable $\mathrm{N}$, specific respiration and macro-organisms) data sets (Doran and Parkin, 1996). The theoretical basis for SOC as a soil fertility estimator is that its high concentration is often associated with high fertility and yield. The contrary is true for soils with low concentrations (Ebanyat, 2009; Mtambanengwe and Mapfumo, 2005; Musinguzi et al., 2013; Zingore et al., 2007). However, some scientists have contested the exclusive use of SOC for the characterization of soil fertility, particularly based on crop yield (Tittonell et al., 2008). Regardless of the schools of thought, there is a general consensus that SOC is an appropriate parameter that integrates the physical, chemical and biological processes in the soil (Carter, 2002), thus giving an edge over the alternative soil fertility assessment techniques. Nonetheless, information on its application in assessing soil fertility and associated crop yield remains very scanty and debatable, particularly under soil conditions that are ameliorated with phosphorus and potassium fertilizer. The objective of this study was, therefore, to evaluate the relevance of the FFE technique in soil productivity assessment and improve its precision using SQR-SOC.

\section{Materials and methods}

\subsection{Study area and research approach}

This study was conducted in Lwamata sub-county, Kiboga district, in Central Uganda, in a wooden savanna agroecological zone (Wortmann and Eledu, 1999). The area has an altitude range of 1100 to $1400 \mathrm{~m}$ a.s.l., with a mean annual temperature of about $25^{\circ} \mathrm{C}$. Total annual rainfall ranges from about 1000 to $1400 \mathrm{~mm}$, and is distributed in a bimodal pattern (Fig. 1). Soils in this area are classified as Ferralsols 
(IUSS Working Group, 2006). The soils are characterized by soil fertility limitations such as low $\mathrm{pH}$, phosphorus and cation exchange capacity.

The study covered two parishes, namely Ssinde and Buninga, selected through farmers and other stakeholders. The villages in Ssinde and Buninga have altitude ranging from 1206 to 1250 and 1113 to $1158 \mathrm{~m}$ a.s.l., respectively. Ssinde is located at $0^{\circ} 53^{\prime} 02.33^{\prime \prime} \mathrm{N}, 31^{\circ} 50^{\prime} 12.48^{\prime \prime} \mathrm{E}$, and Buninga at $0^{\circ} 54^{\prime} 41.55^{\prime \prime} \mathrm{N}, 31^{\circ} 49^{\prime} 52.52^{\prime \prime} \mathrm{E}$. The villages of Lwamirindo and Kagererekamu were selected in Ssinde parish, while the villages of Kikalaala and Kigatansi were selected in Buninga parish.

Based on FFE with soil and crop performance, fields were rated as low, medium and high in soil fertility (Tesfaye et al., 2011). Together with the local farmers and group leaders, a set of criteria was developed to identify farmers with fields suitable for the study. The criteria required that farmers (i) were willing to provide land for the study; (ii) were older than 40 years; and (iii) had working experience with soil fertility and maize crops. Farmers aged 40 years and above were believed to have experience in identifying poor and good fields. Local leaders in each village listed 15 farmers with fields of low, medium and high fertility. From this list, only 8 farmers were randomly selected from the stratified fertility categories. Consequently, a total of 32 farmers from the four villages were chosen and a formal meeting was held to introduce the profiles of the research on rating fields using SOC and FFE. A consensus on the criteria for rating soil fertility was reached. The farmers rated the fields as low $=1$, medium $=2$ and high $=3$, using the following criteria:

- Low/poor fertility category - fields with one or more of the following conditions: low grain yield $\left(<1000 \mathrm{~kg} \mathrm{ha}^{-1}\right)$, stunted plants, nutrient deficiency symptoms, light-colored and/or shallow soils, exposed subsoil, poor tilth (compacted) and very low water holding capacity.

- Medium fertility category - fields with one or more of the following conditions: moderate maize grain yield (at least within the range of $1000-2000 \mathrm{~kg} \mathrm{ha}^{-1}$ ), moderate growth vigor, mild to no nutrient deficiency symptoms, slightly darkish and deep soils, moderate tilth (less compacted), moderate water holding capacity and less evidence of erosion.

- High/good fertility category - fields with one or more of the following conditions: high maize grain yield (> $2000 \mathrm{~kg} \mathrm{ha}^{-1}$ ), high biomass, high growth vigor, good health (dark-green, tall, large plant parts), very darkly colored and deep soil, good tilth (not compacted), high water holding capacity, and without incidences of soil erosion.

Field rating for soil fertility was conducted by each farmer following the set criteria. Farmers identified an extra field (about $20 \mathrm{~m}$ from season 1 fields) for the second-season experiments and accordingly rated its fertility. On-site visits to each proposed farmer's field were made for ground truthing. Initial soil sampling was done for quick laboratory tests for SOC and silt + clay so as to guide the study within the ferralitic properties. Slope gradient was measured using a clinometer, while other field attributes such as slope position, land use and cultivation history were obtained by field observation and information gained from farmers. On average, $80 \%$ of high and medium fields were located in the middle slope position, and $60 \%$ of low-fertility fields were located on the upper slope position. Slope gradients in all fields were $5-16 \%$. All fields were opened for cultivation in the last 2040 years and are often prepared manually with a hand hoe. After the ground-truthing process and characterization, only 15 farmers were finally willing to continue with the research trials: 8 farmers (16 experimental fields) in Ssinde parish and 7 (14 experimental fields) in Buninga parish, making a total of 30 experimental fields for the two seasons.

The second technique to soil fertility rating was the scientific quantitative rating with SOC (SQR-SOC). This included soil sampling, laboratory analysis and participatory fertility rating. Four soil subsamples from each selected farmer's site were collected from 0 to 15 (topsoil) and 15 to $30 \mathrm{~cm}$ (lower soil depth) using an auger. The soil was thoroughly mixed and quarter-sampled prior to taking composite samples for laboratory analyses. Soil texture, $\mathrm{pH}$, Bray 1 extractable $\mathrm{P}$, and exchangeable bases $\left(\mathrm{K}^{+}, \mathrm{Mg}^{2+}, \mathrm{Ca}^{2+}, \mathrm{Na}^{+}\right)$were determined according to the standard methods (Anderson and Ingram, 1993; Okalebo et al., 2002). Soil organic carbon was determined using the wet combustion technique (Walkley and Black, 1934), while total nitrogen was determined using the Kjeldahl distillation and back-titration method at the Makerere University Soil and Plant analytical laboratory. Using SOC concentrations obtained from the laboratory tests, soils were rated into low-, medium- and highfertility categories. The role of SOC is well known in determining nutrient and water holding capacity, improving structure, drainage, aeration, tilth and overall soil health (Carter et al., 2003). Soil organic carbon concentrations in all sampled field ranged from 0.75 to $2.45 \%$. These were categorized into $<1.2 \%$ (low), $1.2-1.7 \%$ (medium) and $>1.7 \%$ SOC (high). The rating was done in reference to the national threshold value of $1.74 \%$ SOC ( $3 \%$ soil organic matter), which is recommended as the critical concentration for sustainable crop production in low-input tropical soils (Okalebo et al., 2002). An equal number of fields $(n=10)$ were rated as low, medium and high fertility with SOC. For FFE, a total of 14,6 , and 10 fields were rated as high, medium and low in fertility.

\subsection{Field experimental lay out and management}

Maize response experiments (using Longe 5) were performed in two seasons (March-May long rains and 
September-November short rains of 2010) on 30 farmers' fields. Experiments were laid out in a factorial, with a "superimposed" split-plot type of arrangement in a randomized complete block Design (RCBD) with farmers' fields as replicates. Each field, rated using FFE and SQR-SOC, was used as a replicate for each of the three categories of low, medium and high (Nokoe, 1992). The "main plots" were represented by the fields clustered as low, medium and high. Nitrogen fertilizer treatments randomly applied represented subplots. For this study, we considered the control plots without $\mathrm{N}$ application, but with $\mathrm{P}$ and $\mathrm{K}$ applications. Other subplots in the whole trial included nitrogen fertilizer treatments at rates of 25,50 and $100 \mathrm{~kg} \mathrm{Nha}^{-1}$. Phosphorus $\left(25 \mathrm{~kg} \mathrm{ha}^{-1}\right)$ and $\mathrm{K}\left(60 \mathrm{~kg} \mathrm{ha}^{-1}\right)$ fertilizers were sourced from triple superphosphate and muriate of potash, respectively. Phosphorus fertilizer was applied at planting, and it was placed in a planting hole (localized placement) so as to ease access of the $\mathrm{P}$ fertilizer by the developing maize roots. Potassiumbased fertilizers were applied in two equal splits at planting and 4 weeks after planting by means of surface broadcasting and incorporating into the soil with a hoe to a depth of approximately $5 \mathrm{~cm}$. Sowing was done by hand and at about 6-8 $\mathrm{cm}$ soil depth at the recommended spacing of $75 \mathrm{~cm}$ inter-row and $25 \mathrm{~cm}$ intra-row, resulting in a population of about 53300 plants ha $^{-1}$. Weeding was done twice during the growing period using a hand hoe. Pests and diseases were not evident, and hence no pesticides were applied. At the end of each season, the plants were harvested in six central rows, leaving one guard row on either sides of each plot. Total biomass (top) and grain yield were measured and expressed on dry weight basis after sun drying for about 15 days. Grains and stovers were subsampled and oven-dried at $70^{\circ} \mathrm{C}$. The oven-dried weight was later on used to adjust both the grain and stover yield to a water content of $140 \mathrm{~g} \mathrm{~kg}^{-1}$. Differences in soil fertility according to the ratings formed the basis for comparing how maize yield responded, under $\mathrm{P}$ and $\mathrm{K}$ nonlimiting conditions.

\subsection{Data analysis}

Using the GenStat software, an exploratory analysis of soil parameters and yield data was initially conducted and variables checked for normality using the Shapiro-Wilk test. Parameters with value $p<0.05$ were transformed with $\log$ $(X+1)$ before proceeding to the next statistical procedure. All soil properties categorized using the SQR-SOC technique in the topsoil and in the lower soil depth were subjected to analysis of variance (ANOVA), and each property was compared using Fisher's least significant difference (LSD) test at the $5 \%$ level of significance. In order to cater for the random effects of farmers' sites, a linear mixed model, using the GenStat restricted maximum likelihood (REML) algorithm directive, was applied (Caliński et al., 2005). The RELM model was also preferred because of the imbalance in the number of replicates associated with each of the fertil- ity rating techniques. It has a robust prediction algorithm to analyze such unbalanced designs. For this study, only yield comparisons from the control (without $\mathrm{N}$ rates) were considered for each of the soil fertility rating techniques. The fixed model terms included the seasons, the fertility rating technique and their interactions (constant + seasons + soil fertility rating + seasons $\times$ soil fertility rating), while the random model comprised the farmer sites. Means were generated for the seasons, each rating technique and their interaction, and these were separated using LSD at $p \leq 0.05$.

In order to establish relationships between yield, SOC and other soil properties from the topsoil and mean concentrations from the top and lower soil depth, multivariate statistical modeling was applied instead of multiple regression models because it considers components of multi-colinearity. A partial least-squares (PLS) regression model was used. The PLS regression model guided the creation of a latent variable model from which all soil properties that influence yield are combined so that it establishes maximum explanation of variation in yield (Esposito Vinzi et al., 2010). All variables were scaled to unit variance prior to PLS modeling. Simple linear regressions were constructed to evaluate the relationships between maize yield and SOC.

\section{Results}

\subsection{Soil productivity rated using farmer field experiences and soil organic carbon techniques}

Soil fertility between and within farmers' fields was highly variable after categorizing the fields using SOC concentrations (SQR-SOC). However, some soil properties such as $\mathrm{pH}$, Bray 1 extractable $\mathrm{P}$, exchangeable $\mathrm{K}^{+}, \mathrm{Ca}^{2+}$, and silt and clay were not significantly different $(p<0.05)$ in the topsoil $(0-15 \mathrm{~cm})$. Below the $15 \mathrm{~cm}$ depth, only $\mathrm{Na}^{+}$and clay exhibited small variations. Soil $\mathrm{pH}$ and silt significantly increased with fertility (Table 1). Total $\mathrm{N}$ significantly increased with soil fertility in both soil depths $(p<0.05)$, registering an almost 2-fold increase in concentration in high-fertility fields as compared to low-fertility fields. Irrespective of soil depth, Bray 1 extractable $\mathrm{P}$ was generally low, far below the critical concentration of $15 \mathrm{mg} \mathrm{kg}^{-1}$ designated for tropical soils (Table 1).

The RELM test for fixed effects demonstrated that both soil fertility ratings, i.e., the FFE and SQR-SOC, are reliable and can predict yield. Both techniques registered significant yield differences $(p<0.05)$ in the rated fields. The seasons did not result in significant yield differences, whereas the interactions with each soil fertility rating technique were significant. Grain yield was not significantly different in medium and high fertility under FFE. However, significant grain yields were registered with the SQR-SOC technique (Table 2). Yield responses were correlating strongly with SQR-SOC compared to the FFE technique. Only 6 farmers 
Table 1. Mean values of soil properties in $0-15$ and $15-30 \mathrm{~cm}$ soil depths for soil fertility categories derived using SOC ratings: low fertility $(<1.2 \%$ SOC), medium fertility $(1.2-1.7 \%$ SOC) and high SOC $(>1.7 \%)$ for 30 sampled fields $(n=10$ for each category) of a Ferralsol in Uganda.

\begin{tabular}{|c|c|c|c|c|c|c|c|c|c|c|}
\hline & \multirow{3}{*}{$\begin{array}{l}\mathrm{pH} \\
\left(\mathrm{H}_{2} \mathrm{O}\right)\end{array}$} & Total & Total & \multirow{3}{*}{$\begin{array}{l}\text { Extractable } \\
\mathrm{P} \text { (Bray 1) } \\
\mathrm{mg} \mathrm{kg}^{-1}\end{array}$} & \multicolumn{6}{|c|}{ Extractable } \\
\hline & & SOC & $\mathrm{N}$ & & $\mathrm{K}^{+}$ & $\mathrm{Na}$ & $\mathrm{Ca}^{2+}$ & $\mathrm{Mg}^{2+}$ & Silt & Clay \\
\hline & & \multicolumn{2}{|c|}{$\%$} & & \multicolumn{4}{|c|}{$\operatorname{cmol}(+) \mathrm{kg}^{-1}$ soil } & $\%$ & \\
\hline \multicolumn{11}{|l|}{$0-15 \mathrm{~cm}$} \\
\hline Low fertility & $5.54^{\mathrm{a}}$ & $0.98^{\mathrm{c}}$ & $0.14^{\mathrm{ab}}$ & $5.3^{\mathrm{a}}$ & $0.22^{\mathrm{a}}$ & $0.073^{\mathrm{ab}}$ & $3.89^{\mathrm{a}}$ & $1.43^{\mathrm{ab}}$ & $12.5^{\mathrm{a}}$ & $21 \mathrm{a}$ \\
\hline Medium fertility & $5.41^{\mathrm{a}}$ & $1.39^{\mathrm{b}}$ & $0.19^{\mathrm{a}}$ & $9.5^{\mathrm{a}}$ & $0.22^{\mathrm{a}}$ & $0.101^{\mathrm{b}}$ & $4.61^{\mathrm{a}}$ & $1.46^{\mathrm{b}}$ & $17.6^{\mathrm{a}}$ & $22 \mathrm{a}$ \\
\hline High fertility & $5.72^{\mathrm{a}}$ & $1.94^{\mathrm{a}}$ & $0.20^{\mathrm{a}}$ & $11.3^{\mathrm{a}}$ & $0.34^{\mathrm{a}}$ & $0.106^{\mathrm{a}}$ & $5.01^{\mathrm{a}}$ & $1.94^{\mathrm{a}}$ & $16.8^{\mathrm{a}}$ & $24 \mathrm{a}$ \\
\hline LSD at $5 \%$ & 0.31 & 0.16 & 0.03 & 6.38 & 0.15 & 0.03 & 1.24 & 0.19 & 5.84 & 7.8 \\
\hline \multicolumn{11}{|l|}{$15-30 \mathrm{~cm}$} \\
\hline Low fertility & $5.42^{\mathrm{ab}}$ & $1.12^{\mathrm{c}}$ & $0.1^{\mathrm{ab}}$ & $4.32^{\mathrm{b}}$ & $0.19^{\mathrm{b}}$ & $0.08^{\mathrm{b}}$ & $4.11^{\mathrm{b}}$ & $1.42^{\mathrm{a}}$ & $13.6^{\mathrm{ab}}$ & $21 \mathrm{a}$ \\
\hline Medium fertility & $5.54^{\mathrm{a}}$ & $1.41^{\mathrm{b}}$ & $0.12^{\mathrm{b}}$ & $8.34^{\mathrm{a}}$ & $0.33^{\mathrm{a}}$ & $0.103^{\mathrm{a}}$ & $4.98^{\mathrm{a}}$ & $2.01^{\mathrm{a}}$ & $18.1^{\mathrm{a}}$ & $24 \mathrm{a}$ \\
\hline High fertility & $5.72^{\mathrm{a}}$ & $2.11^{\mathrm{a}}$ & $0.24^{\mathrm{a}}$ & $12.51^{\mathrm{a}}$ & $0.38^{\mathrm{a}}$ & $0.105^{\mathrm{a}}$ & $5.62^{\mathrm{a}}$ & $2.14^{\mathrm{a}}$ & $19.9^{\mathrm{a}}$ & $26 \mathrm{a}$ \\
\hline LSD at $5 \%$ & 0.24 & 0.22 & 0.06 & 4.91 & 0.17 & 0.026 & 1.22 & 0.27 & 5.41 & 5.11 \\
\hline
\end{tabular}

LSD: least significant difference; ${ }^{\mathrm{a}, \mathrm{b}, \mathrm{c}}$ represent soil properties that are significantly different across low, medium and high soil fertility ( $p<0.05$ ). Same letters along a column represent no significant differences observed on comparing means using the LSD.

Table 2. Maize grain and biomass yield in fields rated using the FFE and SQR-SOC techniques in a Ferralsol in Uganda.

\begin{tabular}{|c|c|c|c|c|}
\hline \multirow[t]{2}{*}{ Rating approaches } & \multirow[t]{2}{*}{$\begin{array}{l}\text { Soil fertility } \\
\text { ratings }(N=30)\end{array}$} & \multirow[t]{2}{*}{$\begin{array}{l}\text { Number of } \\
\text { fields rated }\end{array}$} & $\begin{array}{l}\text { Grain } \\
\text { yield }\end{array}$ & $\begin{array}{l}\text { Biomass } \\
\text { yield }\end{array}$ \\
\hline & & & \multicolumn{2}{|c|}{$\mathrm{kgha}^{-1}$} \\
\hline \multirow[t]{4}{*}{ Farmers' field experiences (FFE) } & Low & 10 & $1113^{b}$ & $6713^{\mathrm{b}}$ \\
\hline & Medium & 6 & $1675^{\mathrm{a}}$ & $8556^{\mathrm{a}}$ \\
\hline & High & 14 & $2042^{\mathrm{a}}$ & $8994^{\mathrm{a}}$ \\
\hline & LSD at $5 \%$ & & 369 & 1012 \\
\hline \multicolumn{5}{|c|}{ Scientific quantitative rating with SOC (SQR-SOC) } \\
\hline & Low $(<1.2 \%$ SOC $)$ & 10 & $1115^{\mathrm{c}}$ & $6121^{\mathrm{b}}$ \\
\hline & Medium (1.2-1.7\% SOC) & 10 & $1554^{\mathrm{b}}$ & $7421^{\mathrm{a}}$ \\
\hline & $\operatorname{High}(>1.7 \%$ SOC $)$ & 10 & $2284^{\mathrm{a}}$ & $8100^{\mathrm{a}}$ \\
\hline & LSD at $5 \%$ & & 244.3 & 1233 \\
\hline
\end{tabular}

LSD: least significant difference; ${ }^{a, b, c}$ represent soil properties that are significantly different across low, medium and high soil fertility $(p<0.05)$. Same letters along a column represent no significant differences observed

on comparing means using the LSD.

rated fields as medium fertility, while 10 and 14 farmers rated the fields as low and high soil fertility, respectively.

\subsection{Reliability of SOC and selected soil parameters in predicting yield}

The PLS model combined different soil parameters into eight latent components. From the two most important components (first and second PLS components), these could be interpreted as "SOC and texture" components, irrespective of soil depth. The first PLS model components explained $49.5 \%$ $(0-15 \mathrm{~cm})$ and $67.3 \%$ (mean concentrations) of the variance in grain yield. The second PLS component explained only
$16.6 \%$ for $0-15 \mathrm{~cm}$ and $2.6 \%$ for mean concentration. Other PLS components explain little variance $(<12 \%)$ in yield to be considered for interpretation. For the first and second PLS components, high percentage of explained variances was obtained for a SOC, silt and clay. The explained variances in topsoil for the first PLS component were $18.2 \%$ for silt and $63.3 \%$ for clay (Table 3 ). A straightforward interpretation of other soil parameters such as $\mathrm{pH}, \mathrm{SOC}$, total $\mathrm{N}, \mathrm{Ca}, \mathrm{Mg}$ was difficult because of little variance. However, in the second PLS component, SOC, total $\mathrm{N}$ and $\mathrm{Mg}$ in the topsoil registered high explained variances of $68.1,51.7$ and $71.1 \%$, respectively. For soil parameters with mean concentrations from 0 to 15 and 15 to $30 \mathrm{~cm}$, a different pattern was no- 
Table 3. Estimates of partial least-squares (PLS) percentage variances for soil parameters and maize grain yield for $0-15 \mathrm{~cm}$ and mean concentration of soil properties from 0 to 15 and 15 to $30 \mathrm{~cm}$ in a Ferralsol in Uganda.

\begin{tabular}{|c|c|c|c|c|c|c|c|c|}
\hline \multirow[b]{2}{*}{ PLS components } & \multicolumn{8}{|c|}{$\%$ of explained variance in grain yield $\left(r^{2}\right)$} \\
\hline & 1 & 2 & 3 & 4 & 5 & 6 & 7 & 8 \\
\hline $0-15 \mathrm{~cm}$ & 49.5 & 16.6 & 12 & 1.3 & 3.9 & 0.1 & 1.5 & 2.2 \\
\hline \multirow[t]{2}{*}{ Mean concentrations (0-15 and 15-30) } & 67.3 & 2.6 & 2 & 1.3 & 3.5 & 0.4 & 1.9 & 0 \\
\hline & \multicolumn{8}{|c|}{$\%$ of explained variances in selected soil properties $\left(r^{2}\right)$} \\
\hline \multicolumn{9}{|l|}{ Topsoil $(0-15 \mathrm{~cm})$} \\
\hline $\mathrm{pH}$ & 4.4 & 9.3 & 9.4 & 2.2 & 63 & 11.7 & 0.0 & 0.0 \\
\hline Total SOC & 9.1 & 68.1 & 10.1 & 6.8 & 0.4 & 5.5 & 0.0 & 0.0 \\
\hline Total N & 5.8 & 51.7 & 4.3 & 7.8 & 3.6 & 10.0 & 15.5 & 1.4 \\
\hline $\log \left(\mathrm{Na}^{+}\right)$ & 0.8 & 0.2 & 0.0 & 2.3 & 3.4 & 0.4 & 11.4 & 81.5 \\
\hline Exchangeable $\mathrm{Ca}^{2+}$ & 4.4 & 34.0 & 51.6 & 8.6 & 1.1 & 0.1 & 0.0 & 0.0 \\
\hline Log (exchangeable $\mathrm{Mg}^{2+}$ ) & 4.4 & 71.1 & 11.5 & 8.4 & 1.3 & 3.3 & 0.0 & 0.0 \\
\hline Silt & 18.2 & 2.1 & 11.5 & 68.2 & 0.0 & 0.0 & 0.0 & 0.0 \\
\hline Clay & 63.3 & 4.6 & 3.0 & 29.2 & 0.0 & 0.0 & 0.0 & 0.0 \\
\hline \multicolumn{9}{|l|}{ Mean concentrations $(0-15$ and $15-30 \mathrm{~cm})$} \\
\hline $\mathrm{pH}$ & 0.3 & 4.1 & 3.0 & 33.5 & 12.2 & 46.8 & 0.0 & 0.0 \\
\hline Total SOC & 72.9 & 0.2 & 4.1 & 0.0 & 22.1 & 0.6 & 0.0 & 0.0 \\
\hline Total N & 58.9 & 0.8 & 8.3 & 0.9 & 18.9 & 2.0 & 8.4 & 1.8 \\
\hline $\log \left(\mathrm{Na}^{+}\right)$ & 0.2 & 1.9 & 8.2 & 1.5 & 1.4 & 8.0 & 17.9 & 60.8 \\
\hline Exchangeable $\mathrm{Ca}^{2+}$ & 57.6 & 0.0 & 34.7 & 7.3 & 0.0 & 0.3 & 0.0 & 0.0 \\
\hline Log exchangeable $\mathrm{Mg}^{2+}$ & 42.9 & 0.2 & 22.4 & 28.4 & 0.1 & 5.9 & 0.0 & 0.0 \\
\hline Silt & 93.1 & 3.8 & 2.3 & 0.7 & 0.0 & 0.1 & 0.0 & 0.0 \\
\hline Clay & 18.4 & 80.4 & 1.1 & 0.1 & 0.0 & 0.0 & 0.0 & 0.0 \\
\hline
\end{tabular}

table. The explained variances for the first PLS component were as high as $93.1 \%$ for silt and $72.9 \%$ for SOC. The third PLS component registered relatively high explained variance for exchangeable bases, particularly $\mathrm{Ca}^{2+}$ exhibiting $51.6 \%$ in the topsoil and $34.7 \%$ for mean concentrations. The response variables for the rest of the PLS components were evident with low values of explained variances.

The PLS loadings showed a positive relationship between grain yield and some soil properties for the first and second PLS components (Table 4). Clay, SOC and silt had the highest loading values irrespective of soil depth, which was consistent with observations listed in Table 3. Other properties had low loading values (weak correlation). In the third PLS component, $\mathrm{Ca}^{2+}$ (topsoil) and $\mathrm{Mg}^{2+}$ (mean concentrations) showed strong negative correlations of -0.946 and -0.6074 , respectively.

The linear regression model fittings explained grain yield variability due to SOC, which accounted for $60.21 \%$ in the topsoil (Fig. 2). The fitted model resulted in $966 \mathrm{~kg} \mathrm{ha}^{-1}$ yield gain per unit increase in SOC for topsoil and about $1223 \mathrm{~kg} \mathrm{ha}^{-1}$ yield gain per unit increase in total SOC considering soil with mean concentrations from 0 to 15 and 15 to $30 \mathrm{~cm}$ (Fig. 2). Similar patterns were obtained for biomass increasing at $3022 \mathrm{~kg} \mathrm{ha}^{-1}$ in the topsoil and $2971 \mathrm{~kg} \mathrm{ha}^{-1}$ for mean concentrations per unit change in SOC.

\section{Discussion}

\subsection{Soil productivity rated using farmers' field experiences and soil organic carbon techniques}

The soil properties in the top and lower soil depth are characteristic of Ferralsols (IUSS Working Group, 2006). Total SOC and $\mathrm{N}$ in both soil depths were sufficient to pinpoint soil fertility categories and yield patterns perceived by the farmers, although $\mathrm{pH}$, Bray 1 extractable $\mathrm{P}$, exchangeable $\mathrm{K}^{+}, \mathrm{Ca}^{2+}$ and texture, varied little in the topsoil. In contrast, soil at $15-30 \mathrm{~cm}$ depth exhibited change in the concentration pattern for the majority of parameters $(\mathrm{pH}$, total $\mathrm{N}$, Bray 1 extractable $\mathrm{P}$, exchangeable $\mathrm{K}^{+}, \mathrm{Ca}^{2+}, \mathrm{Mg}^{2+}$ and silt). This can be attributed to the selective transporting of fine materials arising from continuous soil tillage or organic input applications. This explains the low concentrations observed with other parameters in the topsoil such as SOC and $\mathrm{Ca}^{2+}$ (Table 1). The small changes in clay and silt content, with soil fertility, express the typical nature of sandy loam Kaolinitic Ferralsols (IUSS Working Group, 2006). The influence of SOC on soil properties appeared to be strong in the 
Table 4. Partial least-squares component loadings for soil parameters at $0-15 \mathrm{~cm}$ and mean concentration from 0 to 15 and 15 to $30 \mathrm{~cm}$ in a Ferralsol in Uganda.

\begin{tabular}{lrrrrrrrr}
\hline Topsoil $(0-15 \mathrm{~cm})$ & 1 & 2 & 3 & 4 & 5 & 6 & 7 & 8 \\
\hline $\mathrm{pH}$ & 0.0568 & -0.0007 & -0.2642 & 0.1382 & $-0.5572^{\mathrm{a}}$ & $0.772^{\mathrm{a}}$ & -0.0337 & 0.0178 \\
Total SOC & $0.4028^{\mathrm{b}}$ & $0.5383^{\mathrm{b}}$ & 0.2479 & -0.1421 & $0.5019^{\mathrm{a}}$ & $0.4358^{\mathrm{a}}$ & -0.1506 & 0.0441 \\
Total N & 0.0427 & $0.4581^{\mathrm{b}}$ & 0.0280 & -0.0216 & 0.0816 & 0.1179 & $0.8596^{\mathrm{a}}$ & $-0.4838^{\mathrm{a}}$ \\
$\mathrm{Log}^{\mathrm{N}} \mathrm{Na}^{+}$) & 0.0021 & 0.0024 & 0.0048 & -0.006 & 0.0351 & 0.0289 & 0.4840 & $0.8739^{\mathrm{a}}$ \\
Exchangeable Ca $^{2+}$ & 0.2387 & 0.1672 & $-0.9046^{\mathrm{b}}$ & 0.0922 & 0.2472 & -0.1647 & 0.0059 & -0.0032 \\
Log (exchangeable $\mathrm{Mg}^{2+}$ ) & $0.400^{\mathrm{b}}$ & $0.5512^{\mathrm{b}}$ & 0.1287 & 0.0528 & $-0.585^{\mathrm{a}}$ & $-0.4143^{\mathrm{a}}$ & 0.0547 & 0.0041 \\
Silt & $0.4101^{\mathrm{b}}$ & -0.2852 & 0.1818 & $0.8353^{\mathrm{a}}$ & 0.1392 & -0.0171 & 0.0022 & -0.0017 \\
Clay & $0.669^{\mathrm{b}}$ & 0.242 & -0.0057 & $0.5012^{\mathrm{a}}$ & 0.0839 & 0.0186 & -0.001 & 0.0002 \\
\hline Mean concentrations $(0-15$ and & $15-30 \mathrm{~cm})$ & & & & & & & \\
\hline $\mathrm{pH}$ & -0.0015 & -0.0891 & -0.0826 & -0.3609 & 0.3152 & $-0.8633^{\mathrm{a}}$ & 0.1019 & 0.0079 \\
Total SOC & $0.7847^{\mathrm{b}}$ & 0.1279 & 0.2973 & 0.0360 & 0.1111 & 0.0316 & -0.2657 & 0.074 \\
Total N & $0.4207^{\mathrm{b}}$ & 0.0375 & 0.086 & 0.1296 & 0.2151 & 0.1125 & 0.2793 & -0.3767 \\
Log (Na ${ }^{+}$) & 0.0013 & 0.0071 & 0.0132 & 0.0098 & 0.0271 & 0.0569 & 0.3785 & $0.9233^{\mathrm{a}}$ \\
Exchangeable $\mathrm{Ca}^{2+}$ & 0.3972 & 0.2431 & $0.5871^{\mathrm{b}}$ & -0.634 & 0.0214 & 0.1888 & -0.0171 & -0.0093 \\
Log exchangeable $\mathrm{Mg}^{2+}$ & 0.1371 & -0.2271 & $-0.6074^{\mathrm{b}}$ & $-0.4226^{\mathrm{a}}$ & 0.1530 & 0.1187 & -0.0397 & -0.0081 \\
Silt & $0.8734^{\mathrm{b}}$ & 0.1378 & -0.2905 & 0.2756 & -0.1741 & -0.1636 & 0.0263 & 0.0033 \\
Clay & 0.2186 & $-0.919^{\mathrm{b}}$ & 0.3149 & 0.0791 & -0.0447 & 0.0151 & 0.0012 & 0.0013 \\
\hline
\end{tabular}

$\mathrm{b}$ indicates loadings used to interpret the meaning of first, second, and third PLS components; ${ }^{\mathrm{a}}$ is for the rest of PLS components with moderate to high variances (correlations) $(>0.4)$.

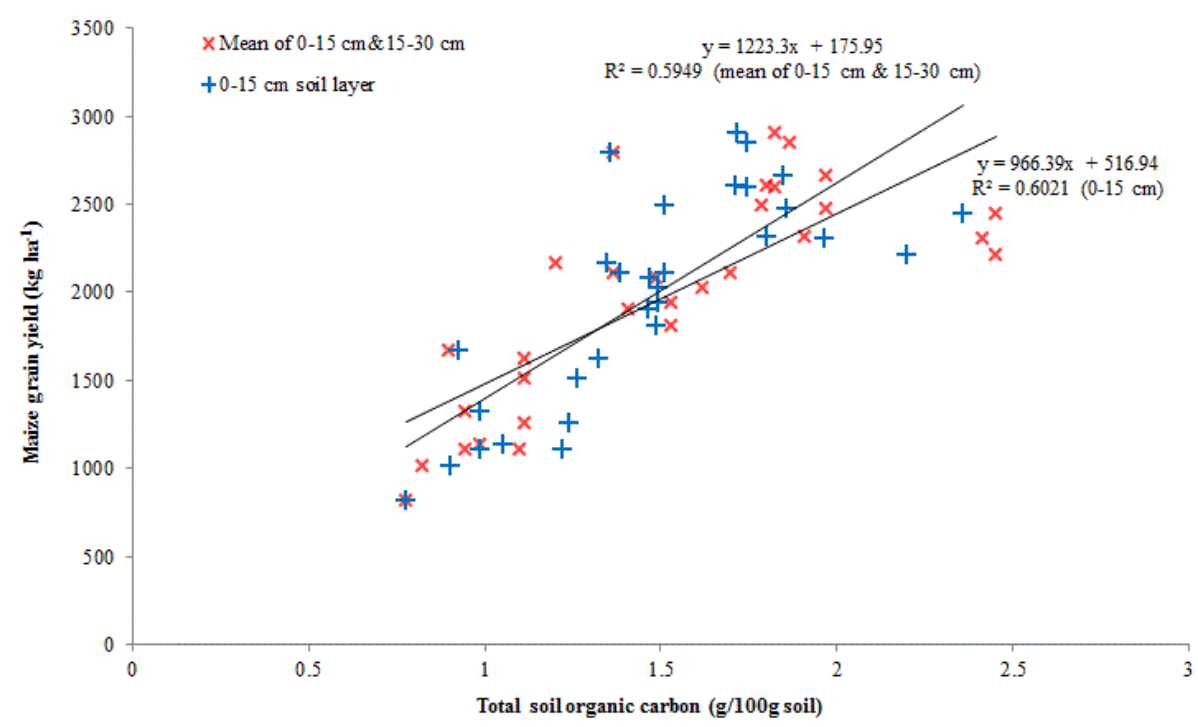

Figure 2. Relationship between maize grain yield and soil organic carbon in a Ferralsol of Uganda.

lower soil depth, which clearly indicates its critical significance in explaining field heterogeneity reported in tropical soils (Ebanyat, 2009; Tittonell et al., 2008). The concurrent increase in clay and SOC with fertility agrees with findings by Feller and Beare (1997), who also reported a positive relationship between clay content and SOC for soil with low activity clay, basically due to increased adsorption sites on the clay mineral surface. Our findings illustrate the importance of SOC in influencing soil functions and chemical fertility, notwithstanding inherently low extractable $\mathrm{P}$ and $\mathrm{pH}$ associated with Ferralsols. SOC is a good benchmark to reflect values on simple rating options that are feasible for farmers.

Positive grain yield patterns obtained in fields rated using FFE and SQR-SOC suggest that both techniques are potentially useful in the identification of poor or good soil among resource-constrained farmers (Table 2). This also agrees with earlier studies that demonstrated that farmers can easily identify different niches of soil fertility (Tittonell et al., 2007; 
Ebanyat, 2009). The capacity of farmers to identify low fertility ascribes to the tendency of most tropical farmers to abandon fields that are believed to be unproductive and nonresponsive (Tittonell and Giller, 2013). The poor yield response in fields of low fertility suggested that ideal SOC concentrations should not be below $1.2 \%$, since this may be insufficient to support crop production in a favorable growing season (Fig. 1). The few farmers who rated medium fertility suggested some difficulty in clearly differentiating such fields from the good field (Table 2). It also showed that the six farmers were possibly more experienced and keen to use the rating criterion. Conversely, it should be noted with precaution that over-reliance on the FFE technique can result in weak fertility judgment and inappropriate management interventions and thus must be used with care. However, farmers' capacity to clearly differentiate low and high fertility fields cannot be overlooked. Such skills and/or experiences are useful in soil fertility management geared towards rural land-use-based policies.

The maize yield pattern indicated farmers' ability to correctly judge soil fertility, with or without scientifically based approaches. This agrees with findings in Ethiopia that exhibited farmers' ingenuity in predicting soil fertility status based on experiences on crop yields, indicator plants, soil color or even soil softness (Karltun et al., 2013; Tesfahunegn et al., 2013). For this study, positive complementarities between indigenous and scientific knowledge can be considered much more reliable in soil fertility rating to plan for measures to combat land degradation (Tesfahunegn et al., 2011). Application of FFE using local knowledge alone is believed to be complex and multi-faceted, with much experiential trial and error (Payton et al., 2003). Reinforcing farmers' knowledge with simple quantifiable scientific indicators is therefore important. The coherent ratings in low-fertility fields in both techniques can be instrumental for easily guiding generalized fertilizer application and fertility restoration strategies (Bekunda et al., 2010; Musinguzi et al., 2014). The findings with FFE technique also suggest that the threshold value of SOC could be lower than $1.2 \%$ from the maize yield predictions. Efforts that can boost SOC building and soil productivity using practices such as integrated soil fertility management are needed (Musinguzi et al., 2013; Vanlauwe and Zingore, 2011). For soils with medium and high fertility, the study suggests that farmers require scientific backing with SOC to overcome uncertainty in identifying such fields (Negatu and Parikh, 1999; Tesfahunegn et al., 2011). Although the FFE technique is known to be rapid, simple, less costly, and of relatively acceptable efficiency, it was only accurate in low-fertility soils and may not be singly applied in soil fertility management (Tesfahunegn et al., 2013). Use of SOC can increase confidence and reliability among tropical farmers. However, other scientific techniques such as assessing nutrient status based upon visual observation of plant deficiency symptoms or based upon the hierarchy of limit- ing nutrients should not be underestimated (Bekunda et al., 2010).

\subsection{Reliability of SOC and selected soil properties in predicting yield}

Yield variance was primarily related to SOC, silt and clay, which can be described as "SOC and texture" components in the PLS model (Table 3). An account of 50\% for the topsoil and $67 \%$ for the mean concentrations of $0-15$ and $15-30 \mathrm{~cm}$ to yield variance reflects the critical role of SOC and texture in influencing soil and crop productivity in a highly heterogeneous environment in SSA (Ebanyat, 2009; Feller and Beare, 1997). The variations in clay and silt in the mean concentrations could be attributed to an increase in content with soil depth, possibly due to continuous cultivation that selectively moves silt or clay into the lower $15-30 \mathrm{~cm}$ depth (Derpsch, 2008). The percentage of unexplained yield variance probably accrues from other factors that limit crop productivity commonly in heterogeneous soils of SSA. Total N was not as influential as SOC, contrary to the significant effects observed with soil fertility (Table 1). This is probably because of the low mineralization potential associated with the soil, which depends on SOC for sustainable productivity (Tiessen et al., 1994). The relationship between clay and SOC (depending on the mineralogy) can also stabilize organic nitrogen, influencing nutrient supply (Bruun et al., 2010). The first PLS loading values attest to these observations of low $\mathrm{N}$ content as compared to SOC (Table 4). The labile $\mathrm{C}$ fraction that has been reportedly depleted in such soils could have influenced total $\mathrm{N}$ supply and yield variance (Musinguzi et al., 2015). Other properties such as $\mathrm{pH}, \mathrm{Ca}, \mathrm{Mg}$ in the first PLS component explained little variance which can be alluded to inherent nature of a Ferralsol, which is typically low in $\mathrm{pH}$ and in cation exchange capacity (IUSS Working Group, 2006).

From the findings, both the topsoil and mean concentrations from 0 to 15 and 15 to $30 \mathrm{~cm}$ soil depths can be reliably used in assessing soil fertility. Okalebo et al. (2002) recommend sampling at a uniform depth of $0-15$ or $0-20 \mathrm{~cm}$. Soil sampling to as deep as $0-30 \mathrm{~cm}$ expressed fertility variability. This could be better than relying on the topsoil alone in field heterogeneity assessment studies for maize production. Perceptions of farmers about soil fertility niches and yield could be boosted with simple scientific options at an appropriate depth, notwithstanding main nutrient limitations to productivity that have remained abstract to farmers (Tittonell et al., 2005).

High maize grain yield gains of $966 \mathrm{~kg} \mathrm{ha}^{-1}$ in the top 0 $15 \mathrm{~cm}$ depth, compared to $1223 \mathrm{~kg} \mathrm{ha}^{-1}$ per unit change of SOC for mean SOC concentrations $(0-15$ and $15-30 \mathrm{~cm})$, demonstrated the influence of soil depth in soil fertility and yield prediction. Mean concentrations of soil parameters registered high responsiveness, and this may be attributed to the high levels of silt + clay and particulate organic matter, 
which is in agreement with the explained variances in the PLS model (Derpsch, 2008; Gregorich et al., 2006; Kapkiyai et al., 1999; Thompson et al., 1991). In line with our findings, similar patterns of maize yield increase with SOC have been reported in Nigeria and Kenya (Kapkiyai et al., 1999; Lal, 1981). In a Kenyan Kikuyu clay soil (Humic Nitisol) and a Nigerian Alfisol, 243 and $254 \mathrm{~kg} \mathrm{ha}^{-1}$ yield gains were registered, respectively. In our findings, yield gains per unit change in SOC were triple those from previous studies where soils are fine-textured. Application of phosphorus and potassium fertilizers could have played a critical role in boosting yield gains in a low-P Ferralsol. Thus, high yield can be obtained in medium- to high-fertility fields with SOC $>1.2 \%$ without use of nitrogen fertilizers when $\mathrm{P}$ and $\mathrm{K}$ nutrientbased fertilizers are added. With the current cost of SOC analysis at Makerere University Soil and Plant laboratory in Uganda at about USD 2.5, as compared to USD 18.5 for the whole spectrum of routine analysis for 9 major soil parameters, considering SOC as a single indicator can save a farmer colossal sums of money associated with laboratory analysis.

\section{Conclusions}

Both the FFE and SQR-SOC soil fertility rating techniques consistently demonstrated a high capacity to predict maize yields in a Ferralsol. The FFE technique was inefficient in fields with SOC above $1.2 \%$ (medium and high fertility) but was accurate in rating low fertility $(<1.2 \%$ SOC). A large variation in yield was accounted for by SOC and texture, which was consistent with soil depth. Each unit increase in SOC concentration resulted in triple grain yield gains under $\mathrm{P}$ - and $\mathrm{K}$-ameliorated soil conditions, which is higher than what is reported in other studies in Africa. Using field experiences of resource-poor farmers, coupled with simple but affordable scientific quantitative techniques such as SOC testing, can enhance farmers' precision in decision making for soil fertility improvement. However, SOC must be used with caution considering other factors that lead to unexplained yield variances. In the case of significant anomalies in using SOC for maize yield predictions, detailed laboratory tests are unavoidable.

Acknowledgements. The authors thank the World Phosphate Institute (IMPHOS) for providing field research funds. We thank the farmers who provided us land to conduct the experiments. The authors would like to thank the anonymous referees for a range of supportive and constructive comments that helped in improving this paper.

Edited by: A. Cerdà

\section{References}

African Agriculture Status Report: Focus on Staple Food Crops, Alliance for a Green Revolution in Africa, Alliance for a Green Revolution in Africa (AGRA), Nairobi, Kenya, 44-46, 2013.

Anderson, J. and Ingram, J.: Tropical Soil Biology and Fertility: a Handbook of Methods, CAB International, Wallingford, UK, 221 pp., 1993.

Andrews, S. S., Karlen, D. L., and Cambardella, C. A.: The soil management assessment framework, Soil Sci. Soc. Am. J., 68, 1945-1962, doi:10.2136/sssaj2004.1945, 2004.

Araya, A., Stroosnijder, L., Girmay, G., and Keesstra, S. D.: Crop coefficient, yield response to water stress and water productivity of teff (Eragrostis tef (Zucc.), Agr. Water Manage., 98, 775-783. 2011.

Barua, S. K. and Haque, S. M. S.: Soil characteristics and carbon sequestration potentials of vegetation in degraded hills of Chittagong, Bangladesh, Land Degrad. Dev., 24, 63-71, doi:10.1002/ldr.1107, 2013.

Bekunda, M., Sanginga, N., and Woomer, P. L.: Restoring soil fertility in sub-Sahara Africa, Adv. Agron., 108, 183-236, 2010.

Brevik, E. C., Cerdà, A., Mataix-Solera, J., Pereg, L., Quinton, J. N., Six, J., and Van Oost, K.: The interdisciplinary nature of SOIL, SOIL, 1, 117-129, doi:10.5194/soil-1-117-2015, 2015.

Bruun, T. B., Elberling, B., and Christensen, B. T.: Lability of soil organic carbon in tropical soils with different clay minerals, Soil Biol. Biochem., 42, 888-895, 2010.

Caliński, T., Czajka., S., Kaczmarek, Z., Krajewski, P., and Pilarczyk. W.: Analyzing multi-environment variety trials using randomization-derived mixed models, Biometrics, 61, 448-455, 2005.

Carter, M. R.: Soil quality for sustainable land management, Agron. J., 94, 38-47, 2002.

Carter, M., Angers, D., Gregorich, E., and Bolinder, M.: Characterizing organic matter retention for surface soils in eastern Canada using density and particle size fractions, Can. J. Soil Sci., 83, 11-23, doi:10.4141/S01-087, 2003.

Corbeels, M., Shiferaw, A., and Haile, M.: Farmers' knowledge of soil fertility and local management strategies in Tigray, Ethiopia, IIED-Drylands Programme, December 2000.

Derpsch, R.: No-tillage and conservation agriculture: a progress report, in: No-Till Farming Systems, edited by: Goddard, T., Zoebisch, M. A., Gan, Y. T., Ellis, W., Watson, A., and Sombatpanit, S., World Association of Soil and Water Conservation, Bangkok, 7-39, 2008.

Doran, J. W. and Parkin, T. B.: Quantitative indicators of soil quality: a minimum data set, SSSA Spec. Publ., 49, 25-38. 1996

Ebanyat, P.: A road to food? Efficacy of nutrient management options targeted to heterogeneous soilscapes in the Teso farming system, Uganda, PhD Thesis, Wangenigen, the Netherlands, 4574, 2009.

Esposito Vinzi, V., Chin, W. W., Henseler, J., and Wang, H.: Handbook of partial least squares: Concepts, methods and applications, Springer, 691-711. 2010.

Feller, C. and Beare, M.: Physical control of soil organic matter dynamics in the tropics, Geoderma, 79, 69-116, 1997

Gregorich, E. G., Beare, M. H., McKim, U. F., and Skjemstad, J. O.: Chemical and biological characteristics of physically uncomplexed organic matter, Soil Sci. Soc. Am. J. 70, 975-985, doi:10.2136/sssaj2005.0116, 2006. 
IFDC: Africa fertilizer summit proceedings, Abuja, Nigeria, 9-13 June, 2006.

IUSS Working Group: World reference base for soil resources, World Soil Resources Report, No. 103, FAO, Rome, Italy, 7879, 2006.

Karltun, E., Lemenih, M., and Tolera, M.: Comparing farmers' perception of soil fertility change with soil properties and crop performance In Beseku, Ethiopia, Land Degrad. Dev., 24, 228-235, doi:10.1002/ldr.1118, 2013.

Kapkiyai, J. J., Karanja, N. K., Qureshi, J. N., Smithson, P. C., and Woomer, P. L.: Soil organic matter and nutrient dynamics in a Kenyan Nitisol under long-term fertilizer and organic input management, Soil Biol. Biochem., 31, 1773-1782, 1999.

Keesstra, S. D., Geissen, V., van Schaik, L., Mosse., K., and Piiranen, S.: Soil as a filter for groundwater quality, Current Opinions in Environmental Sustainability, 4, 507-516, doi:10.1016/j.cosust.2012.10.007, 2012

Kukal, S. S., Saha, D., Sharma, P., and Sharma, B. D.: Profile distribution of carbon fractions under long-term rice-wheat and maizewheat production in Alfisols and Inceptisols of northwest India, Land Degrad. Dev., doi:10.1002/ldr.2299, 2014.

Lal, R.: Soil erosion problems on Alfisols in Western Nigeria VI, Effects of erosion on experimental plots, Geoderma, 25, 215230, doi:10.1016/0016-7061(81)90037-9, 1981.

Lal, R.: Enhancing crop yields in the developing countries through restoration of the soil organic carbon pool in agricultural lands, Land Degrad. Dev.. 17, 197-209, doi:10.1002/ldr.696, 2006.

Lorenz, K. and Lal, R.: Soil organic carbon sequestration in agroforestry systems, A review, Agron. Sustain. Dev., 34, 443-454, 2014.

Mtambanengwe, F. and Mapfumo, P.: Organic matter management as an underlying cause for soil fertility gradients on smallholder farms in Zimbabwe, Nutr. Cycl. Agroecosys., 73, 227-243, 2005.

Musinguzi, P., Ebanyat, P., Tenywa, J.S., Mwanjalolo, M., Basamba, T. A., Tenywa, M. M., and Porter, C.: Using DSSATCENTURY Model to Simulate Soil Organic Carbon Dynamics Under a Low-Input Maize Cropping System, J. Agr. Sci., 6, 120131, doi:10.5539/jas.v6n5p120, 2014.

Musinguzi, P., Tenywa, J. S., Ebanyat, P., Basamba, T. A., Tenywa, M. M., Mubiru, D. N., and Zinn, Y. L.: Soil organic fractions in cultivated and uncultivated Ferralsols in Uganda, Geoderma Regional, 4, 108-113, 2015.

Musinguzi, P., Tenywa, J. S., Ebanyat, P., Tenywa, M. M., Mubiru, N. D, Twaha, A. B., and Adrian, L.: Soil Organic Carbon Thresholds and Nitrogen Management in Tropical Agroecosystems: Concepts and Prospects, Journal of Sustainable Development, 6, 31-43. doi:10.5539/jsd.v6n12p31, 2013.

Negatu, W. and Parikh, A.: The impact of perception and other factors on the adoption of agricultural technology in the Moret and Jiru Woreda ( district) of Ethiopia, Agric. Econ. 21, 205-216, doi:10.1016/S0169-5150(99)00020-1, 1999.

Nokoe, S.: Technical paper 7: Statistical and experimental design considerations in alley farming, in: The AFNETA Alley Farming Training Manual, edited by: Tripathi, B. R. and Psychas, P. J., International Livestock Centre for Africa, Addis Ababa, Ethiopia, 1-34, 1992.

Novara, A., Gristina, L., Guaitoli, F., Santoro, A., and Cerdà, A.: Managing soil nitrate with cover crops and buffer strips in $\mathrm{Si}$ - cilian vineyards, Solid Earth, 4, 255-262, doi:10.5194/se-4-2552013, 2013.

Okalebo, J., Gathua, K., and Woomer, P.: Laboratory methods of plant and soil analysis: a working manual, TSBF-UNESCO, Nairobi, Kenya, 128 pp., 2002.

Payton, R., Barr, J., Martin, A., Sillitoe, P., Deckers, J. Gowing, J., Hatibu, N., Naseem, S., Tenywa, M. and Zuberi, M.: Contrasting approaches to integrating indigenous knowledge about soils and scientific soil survey in East Africa and Bangladesh, Geoderma, 111, 355-386, doi:10.1016/S0016-7061(02)00272-0, 2003.

Rinivasarao, C., Venkateswarlu, B., Lal, R., Singh, A. K., Kundu, S., Vittal, K. P. R., Patel, J. J., and Patel, M. M.: Long-term manuring and fertilizer effects on depletion of soil organic carbon stocks under pearl millet-cluster bean-castor rotation in Western India, Land Degrad. Dev., 25, 173-183, 2014.

Sanginga, N. and Woomer, P. L.: Integrated soil fertility management in Africa: principles, practices, and developmental process: Tropical Soil Biology and Fertility Institute of the International Centre for Tropical Agriculture, Nairobi, Kenya, 263 pp., 2009.

Schoonmaker Freudenberger, K.: Challenges in the collection and use of information on livelihood strategies and natural resource management, Beyond Farmer First, Intermediate, London, UK, 1994.

Shazana, M. A. R. S., Shamshuddin, J., Fauziah, C. I., and Syed Omar, S. R: Alleviating the infertility of an acid sulphate soil by using ground basalt with or without lime and organic fertilizer under submerged conditions, Land Degrad. Dev., 24, 129—140, doi:10.1002/ldr.1111, 2013.

Shepherd, K. D., Palm, C. A., Gachengo, C. N., and Vanlauwe, B:. Rapid characterization of organic resource quality for soil and livestock management in tropical agroecosystems using nearinfrared spectroscopy, Agron. J., 95, 1314-1322. 2003.

Talawar, S. and Rhoades, R. E.: Scientific and local classification and management of soils, Agr. Hum. Values, 15, 3-14, doi:10.1023/A:1007497521205, 1998.

Tesfahunegn, G. B., Tamene, L., and Vlek, P. L.: A participatory soil quality assessment in Northern Ethiopia's Mai-Negus catchment, Catena, 86, 1-13, doi:10.1016/j.catena.2011.01.013, 2011.

Tesfahunegn, G. B., Tamene, L., Vlek, P. L., and Mekonnen, K.: Assesing farmers' knowledge of weed species, crop type and soil management practices in relation to soil quality status in Mai-Negus Catchment, Northern Ethiopia, Land Degrad. Dev., doi:10.1002/ldr.2233, 2013.

Tesfaye, A., Githiri, M., Derera, J., and Debele, T.: Subsistence farmers' experience and perception about the soil, and fertilizer use in Western Ethiopia, Ethiopian Journal of Applied Sciences and Technology (EJAST), 2, 61-74, 2011.

Tesfaye, M. A., Bravo-Oviedo, A., Bravo, F., Kidane, B., Bekele, K., and Sertse, D.: Selection of tree species and soil management for simultaneous fuelwood production and soil rehabilitation in the ethiopian central highlands, Land Degrad. Dev., doi:10.1002/ldr.2268, 2014.

Thompson, A., Gantzer, C., and Anderson, S.: Topsoil depth, fertility, water management, and weather influences on yield, Soil Sci. Soc. Am. J., 55, 1085-1091, doi:10.2136/sssaj1991.03615995005500040032x, 1991.

Tiessen, H., Cuevas, E., and Chacon, P.: The role of soil organic matter in sustaining soil fertility, Nature, 371, 783-785, 1994. 
Tittonell, P. and Giller, K. E.: When yield gaps are poverty traps: the paradigm of ecological intensification in African smallholder agriculture, Field Crop. Res., 143, 76-90, 2013.

Tittonell, P., Vanlauwe, B., Leffelaar, P., Rowe, E., and Giller, K.: Exploring diversity in soil fertility management of smallholder farms of western Kenya, heterogeneity at region and farm scales, Agr. Ecosyst. Environ., 110, 149-165, 2005.

Tittonell, P., Vanlauwe, B., De Ridder, N., and Giller, K. E.: Heterogeneity of crop productivity and resource use efficiency within smallholder Kenyan farms: soil fertility gradients or management intensity gradients?, Agr. Syst., 94, 376-390, doi:10.1016/j.agsy.2006.10.012, 2007.

Tittonell, P., Shepherd, K. D., Vanlauwe, B., and Giller, K. E.: Unravelling the effects of soil and crop management on maize productivity in smallholder agricultural systems of western Kenya - 1An application of classification and regression tree analysis, Agr. Ecosyst. Environ., 123, 137-150, doi:10.1016/j.agee.2007.05.005, 2008.
Vanlauwe, B. and Zingore, S.: Integrated soil fertility management: An operational definition and consequences for implementation and dissemination, Better Crops, 95, 4 pp., 2011.

Walkley, A. and Black, I. A: An examination of the Degtjareff method for determining soil organic matter, and a proposed modification of the chromic acid titration method, Soil Sci., 37, 29 37, doi:10.1097/00010694-193401000-00003, 1934.

Wortmann, C. S. and Eledu, C. A.: Uganda's Agro Ecological Zones: A Guide For Planners and Policy Makers, CIAT, Kampala, Uganda, 1999.

Zingore, S., Murwira, H., Delve, R., and Giller, K.: Influence of nutrient management strategies on variability of soil fertility, crop yields and nutrient balances on smallholder farms in Zimbabwe, Agr. Ecosyst. Environ., 119, 112-126, 2007. 